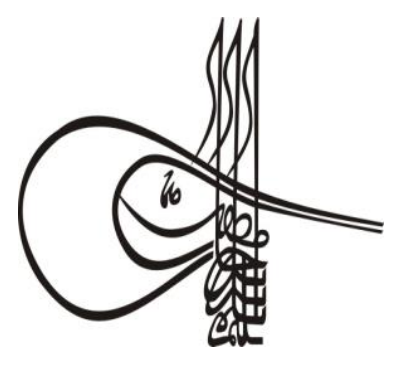

Received/Geliș: 06.10.2019
Turkigh Studies

Volume 14 Issue 7, 2019, p. 4071-4085

DOI: 10.29228/TurkishStudies.38868

ISSN: $1308-2140$

Skopje/MACEDONIA-Ankara/TURKEY

Research Article / Araștırma Makalesi

Article Info/Makale Bilgisi

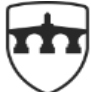

INTERNATIONAL BALKAN UNIVERSITY

EXCELLENCE FOR THE FUTURE IBU.EDU.MK

Go Report Dates/Rapor Tarihleri: Referee 1 (05.11.2019)-Referee 2 (30.12.2019)

This article was checked by iThenticate.

\title{
T.Ü. İLHAN KOMAN HEYKEL VE RESIMM MÜZESİ; SEÇİLMISŞ ESER ÇÖZÜMLEMELERİ
}

\author{
Melihat TÜZÜN*
}

\begin{abstract}
ÖZ
İlhan Koman Heykel ve Resim Müzesi, Trakya Üniversitesinin kuruluşunun 20. yılı olan 23 Eylül 2002 tarihinde "Çağdaş Resim ve Heykel Müzesi” adıyla kurulmuş, 2011 yılında Üniversite Senatosunun karar ile "İlhan Koman Heykel ve Resim Müzesi" adını almıștır. Aynı yıl, Eski Gar Binası, Lozan Anıtı ve Meydanı, Milli Mücadele ve Lozan Müzesi'nin de bulunduğu, Güzel Sanatlar Fakültesi Karaağaç yerleşkesindeki tarihi köşke taşınmıştır.

Müze koleksiyonunda, adını aldığı dünyaca ünlü Edirne'li heykeltraș İlhan Koman başta olmak üzere, sanat tarihinde yerini almış, pek çok önemli sanatçının eserleri yer almaktadır. Müze koleksiyonu tamamen bağış yoluyla elde edilmiştir. Bu eserler arasında Burhan Doğançay, Adil Doğançay, Devrim Erbil, Mehmet Pesen, Burhan Yıldırım, Basri Erdem, Bahattin Odabaş1, Onay Akbaş, Numan Pura, Mustafa Plevneli, Güngör D. Arıbal, Fehim Huskovic, Nikolay Alexiev, Orhan Benli, Hakan Esmer, Halim Çeliker, Habib Gerez, Mustafa Aslıer, İsmail Avc1, Hayri Esmer, Hasan Pekmezci, Atilla Atar, Tülin Onat, Hatice Bengisu, Süleyman Saim Tekcan vb. gibi önemli sanatçıların heykel, resim ve baskıresim eserleri bulunmaktadır.

Müze koleksiyonu, yağlıboya resim bașta olmak üzere baskıresim, suluboya, karışık teknikle yapılan tablolar ve heykellerden oluşur. Koleksiyonda, 2019 yılı başı itibarı ile 376 sanatçının 22 farklı teknikle 685 eseri bulunmaktadir.

$\mathrm{Bu}$ araştırmada, müze koleksiyonunu oluşturan ve Türk plastik sanatlarında önemli yeri olan sanatçıların, müzede bulunan eserleri görsellerle açıklanacak, koleksiyonun üniversite ve Türk plastik sanatları açısından önemi üzerinde durulacaktır.
\end{abstract}

Anahtar Kelimeler: Müze, Sanat, Heykel, Resim, Baskıresim 


\title{
T.U. ILHAN KOMAN SCULPTURE AND PAINTING MUSEUM; SELECTED WORKS ANALYSIS
}

\begin{abstract}
İlhan Koman Sculpture and Painting Museum was established on September 23, 2002, the 20th year of the establishment of Trakya University, under the name of "Contemporary Painting and Sculpture Museum. In the same year, the Old Station Building, Lausanne Monument and Square, the National Struggle and Lausanne Museum, including the Faculty of Fine Arts Karaağaç campus moved to the historic mansion.

In the museum collection, there are works of many important artists who took their place in the history of art, especially the sculptor İlhan Koman from Edirne. The museum collection was fully acquired through donations. Among these works are Burhan Doğançay, Adil Doğançay, Devrim Erbil, Mehmet Pesen, Burhan Yıldırım, Basri Erdem, Bahattin Odabaş1, Onay Akbaş, Numan Pura, Mustafa Plevneli, Güngör D. Arıbal, Fehim Huskovic, Nikolay Alexiev, Orhan Benli, Hakan Esmer, Halim Çeliker, Habib Gerez, Mustafa Aslier, İsmail Avc1, Hayri Esmer, Hasan Pekmezci, Atilla Atar, Tulin Onat, Hatice Bengisu, Süleyman Saim Tekcan and so on. Sculpture, painting and printmaking works of such important artists.

The museum collection consists of oil painting, printmaking, watercolor, mixed media paintings and sculptures. As of the beginning of 2019, 376 artists have 685 works in 22 different techniques.

In this research, the works of the artists who make up the museum collection and have an important place in Turkish plastic arts will be explained with visuals and the importance of the collection in terms of university and Turkish plastic arts will be emphasized.
\end{abstract}

\section{STRUCTURED ABSTRACT}

\section{Introduction}

İlhan Koman Sculpture and Painting Museum is located in Karaağaç Campus of the Faculty of Fine Arts of Trakya University. The museum hosts works of important artists from Turkey and the Balkans.

In the museum collection, there are works of many important artists who took their place in the history of art, especially Illhan Koman, the world famous sculptor from Edirne. There are 685 artworks in the museum collection, which are completely obtained through donations. Among these are the sculpture, painting and printmaking works of Burhan Doğançay, Adil Doğançay, Basri Erdem, Devrim Erbil, Mehmet Pesen, Onay Akbaş, Mustafa Plevneli, Fehim Huskovic, Nikolay Alexiev, Gerez, Mustafa Aslier, Tulin Onat, Süleyman Saim Tekcan, and so on.

Qualitative and quantitative research method was used in this research. The artists who were included in this research and whose works were included in the museum collection were searched by literature and internet browsing method. The works of the artists in the museum 
collection were interpreted by iconographic analysis method. The artists and their works included in the research are some of the works that have an important place in the history of Turkish plastic arts and are thought to add value to the collection. The museum collection is very important for Trakya University and Turkish plastic arts.

İlhan Koman Sculpture and Painting Museum Collection hosts works of many important artists who took their place in the history of art, especially the world famous Edirne sculptor İlhan Koman. In the beginning of 2019, there are 685 works of 376 artists in 22 different techniques. About one-third of the collection consists of oil paintings. It is followed by printmaking, watercolor and mixed media.

\section{Elected Artwords and Their Analyes}

\subsection{Selection From Sculpture Art}

İlhan Koman Sculpture and Painting Museum has 35 sculptures of 16 artists in the collection.

Statue of Pi (1984) - IIhan KOMAN (1921-1986); Nine works Sculptor İlhan Koman from Edirne were donated by his family to the museum. These are 1 bust, 2 tors, 5 reliefs and 1 Four Pi statues. Pi made of thin metal sheet and painted in white. By creating pi-containing surfaces, Ilhan Koman carried out works whose surfaces were formed by multiplication of pi number but the diameter of the circle remained the same. The surfaces formed using many pi surfaces are folded and intertwined, forming a poetic sphere composed of layers of surfaces connecting the center and the periphery. Pi series sculptures are the works where science and art meet and mathematics is embodied with sculpture. (Figure 1)

The Blue Process (1993) - Meriç HIZAL (1943-...); The work "Blue Process" which can be found in the Museum Collection is a structure created with geometric shapes by using wood and polyester material together. Pyramidal triangle symbolize the rise to the sky. (Figure 2)

\subsection{Selection From Paintings}

Nearly half of the museum's collection consists of oil paintings. Many famous artist's paintings from Turkey and world add value to the museum. 362 oil paintings by 193 artists are exhibited alternately.

Can't Buy Me Love (1997) - Burhan DOĞANÇAY (1929-2013); Burhan Doğançay, with an abstract-conceptual understanding of art, made use of the visual effects of torn and worn paper advertisements on the walls and searched for space and the third dimension in his canvases. The artist's work "Can't Buy Me Love" in the museum collection is made with mixed media on canvas and is the most valuable work. Espas opens from the canvas surface towards the auidience. (Figure 3)

Art for Life (1997) - Deurim ERBILL (1937-...); Devrim Erbil is one of the rare Turkish painters whose works are sold for a high amount of money The in the museum are flying birds isolated in a monochrome pattern. The painting, which makes movement on the surface, makes the rhythm of the flying birds where the line and the spot stains come to the fore, reminds us of the migration of birds. The work which Erbil calls "Art for Life" includes many meanings. The artist, whose subject and 
inspiration is from natural life, integrates existence and life into art. (Figure 4)

The Bride (2000) - Mehmet PESEN (1923-2012); His work in the museum tells of the Anatolian village wedding. Bride is being taken to her husband's home on a white horse with a flag. It is significant that there are no men in the picture, except for the girls who are accompanied by the bride and the peasant women and children dressed in shalwar around. (Figure 5)

Untitled (1992) - Hüseyin ALTAYLI (1935-2014); Hüseyin Altaylı draws attention to nature and especially the theme of Istanbul in his works. His work in the museum has two sailboats colliding. There are two boats with folded canvases and sailors holding ores. The blue color that dominates the whole picture was added to the pastel painting in two tones. (Figure 6)

Going (2002) - Onay AKBAŞ (1964- ...); Onay Akbas, in his paintings, interrogates the Powers (hunting-hunter, game-toy). Human and everything about the human (game, hierarchy, power) can be among the issues. In his work at the Museum, we see a struggle between two figures. In fact, the figure in front has taken the power and dragging the other towards himself, not wanting him to go. (Figure 7)

\subsection{Selection From Printmaking}

Mustafa Aslier and many of the original printmaking artists from Turkey and the Balkans are exhibited in the museum collection. The museum has 65 collections of printmaking in 65 different techniques by 41 artists.

Twins (2012) - Mustafa ASLIER (1926-2015); Mustafa Aslier used metal engraving technique with a geometric abstracting attitude, blackand-white and sometimes colorful approach in his local figures. In the engraving called Twins in the museum, local elements are used and figures are made as simple as possible. This engraving seems to show a moment from the tales of Keloğlan. Keloğlan on his donkey is waving to twin sisters who have turned their backs. Yet noone has neither seen not heard him. (Figure 8)

Tablets II (2000) - Süleyman Saim Tekcan (1940-...); The museum has three engravings called "Tablets". "Tablet II" is a metal engraving with a half-body of the horse in the center in the form of a tombstone and Ottoman inscriptions on the top and bottom. The inscriptions on the horse were designed in four different plans and an old coin draw attention on the left. (Figure 9)

\subsection{Selections From Photography}

There are 5 photographic works by 5 artists in the museum collection. The most important and noteworthy is Burhan Doğançay's special edition big-size photograph.

Montparnesse-Paris (1981) - Burhan DOĞANÇAY (1929-2013); In the private and certified printed photo, there is a male with a suitcase in one hand and a folded bed in the other staring at the camera. A man with a mustache, apparently dressed in 5 layers of clothing, is apparently 
suffering from the burden of life. On the left is a figure with a bag in his hands. (Figure 10)

\section{Conclusion}

Trakya University İlhan Koman Museum of Sculpture and Painting is an indispensable stopover point for visitors from Edirne, Balkans and other regions. The museum's collection consists of works of artists who have an important place in Turkish plastic arts. As it is a museum located at the Karaağaç Historical Train Station, which receives hundreds of visitors every day, the number of visitors increases day by day and it acts as a very important bridge for the art to reach the public. Moreover, the fact that it is adjacent to a faculty providing fine arts education gives young people the opportunity to see different works together and directly contributes to education.

The Museum, which brings together the most important artists of a period and makes them seen in the same place and time, enables us to evaluate, interpret and understand the works of artists working in different genres and techniques together.

As a result, Trakya University İlhan Koman Sculpture and Painting Museum, which is very important in terms of Turkish plastic arts, is aiming to become a light for future generations by increasing its collections.

Keywords: Museum, Art, Sculpture, Painting, Printmaking

\section{Giriş}

Trakya Üniversitesi Güzel Sanatlar Fakültesi Karaağaç yerleşkesinde bulunan İlhan Koman Heykel ve Resim Müzesi, Türkiye ve balkanlardan önemli sanatçlların eserlerine ev sahipliği yapmaktadır.

Trakya Üniversitesinin kuruluşunun 20. y1lı olan 23 Eylül 2002 tarihinde "Çağdaş Resim ve Heykel Müzesi” adıyla kurulmuş, 2011 yılında Üniversite Senatosunun karar ile şu anki adını almıştır. Aynı yıl, Eski Gar Binası, Lozan Anıtı ve Meydanı, Milli Mücadele ve Lozan Müzesi'nin de bulunduğu, Güzel Sanatlar Fakültesi Karaağaç yerleşkesinde bulunan tarihi köşke taşınmıştır.

Müze koleksiyonunda, adını aldığı dünyaca ünlü Edirneli heykeltıraş İlhan Koman başta olmak üzere, sanat tarihinde yerini almış, pek çok önemli sanatçının eserleri yer almaktadır. Tamamen bağış yoluyla elde edilen müze koleksiyonunda 685 eser vardır. Bu eserler arasında Burhan Doğançay, Adil Doğançay, Burhan Yıldırım, Basri Erdem, Bahattin Odabaşı, Devrim Erbil, Mehmet Pesen, Onay Akbaş, Numan Pura, Mustafa Plevneli, Güngör D. Arıbal, Fehim Huskovic, Nikolay Alexiev, Orhan Benli, Hakan Esmer, Halim Çeliker, Habib Gerez, Mustafa Aslier, İsmail Avcı, Hayri Esmer, Hasan Pekmezci, Atilla Atar, Tülin Onat, Hatice Bengisu, Süleyman Saim Tekcan vb. gibi önemli sanatçıların heykel, resim ve baskıresim eserleri bulunmaktadır.

Marmara Üniversitesi Öğretim Üyeleri Prof. Dr. Ayla Ersoy, Prof. Dr. Ali Candaş ve Prof. Dr. Basri Erdem'in danışmanlığında oluşturulan müzedeki eserlerin tamamı sanatçılar tarafindan bağışlanmıştır.

\section{Materyal ve Yöntem}

$\mathrm{Bu}$ araştırmada, nitel ve nicel araştırma yöntemi kullanılmıştır. Müze koleksiyonunda eserleri olan ve bu araştırmaya dahil edilen sanatçılar literatür ve internet tarama yöntemiyle 
araştırılmıştır. Araştırmada yer alan sanatçıların müze koleksiyonun yer alan eserleri ikonografik çözümleme yöntemi ile yorumlanmıştır. Araştırmaya dâhil edilen sanatçı ve eserleri, Türk plastik sanatları tarihinde önemli yeri olan ve koleksiyona değer kattığı düşünülen eserlerden bir kısmıdır.

\section{1. İlhan Koman Heykel ve Resim Müzesi Koleksiyonu}

Müze koleksiyonunda, dünyaca ünlü Edirneli heykeltıraş İlhan Koman başta olmak üzere, sanat tarihinde yerini almış, pek çok önemli sanatçının eserleri yer almaktadır.

Müzede 2019 yılı başı itibarı ile 376 sanatçının 22 farklı tekniklerde aşağıda tabloda belirtildiği gibi 685 eseri bulunmaktadır. Koleksiyonun yaklaşık üçte birini yağlıboya tablolar oluşturur. Onu baskıresim, suluboya ve karışık teknikle yapılan tablolar takip eder.

Tablo 1: Müze Koleksiyonun Mevcut Eser Sayısı

\begin{tabular}{|ccc|}
\hline SANATÇI SAYISI & ESER TEKNIĞİ & ESER SAYISI \\
\hline 193 & Yağlı Boya & 362 \\
\hline 36 & Karışı Teknik & 43 \\
10 & Pastel Boya & 25 \\
\hline 5 & Fotoğraf & 5 \\
\hline 1 & Motif Çalışması & 20 \\
\hline 3 & Seramik & 7 \\
\hline 6 & Karakalem & 35 \\
\hline 16 & Heykel & 65 \\
\hline 1 & Baskı & 18 \\
\hline 33 & Akrilik & 60 \\
\hline 2 & Sulu Boya & 15 \\
\hline 3 & Desen & 5 \\
\hline 1 & Çini & 9 \\
\hline 1 & Süsleme Yazı & 1 \\
\hline 1 & Kolaj & 1 \\
\hline 1 & Ebru & 1 \\
\hline 1 & Minyatür & 1 \\
\hline 1 & Bakır oyma & 1 \\
\hline 1 & Cam Füzyon & 1 \\
\hline Sanatç1: 376 & Ahşap & 1 \\
\hline
\end{tabular}

\section{Seçilmiş Eser ve Çözümlemeleri}

\subsection{Heykel Sanatından Seçki}

İlhan Koman Heykel ve Resim Müzesi koleksiyonunda 16 sanatçının 35 heykeli vardır. Koleksiyonda heykelleri yer alan, İlhan Koman, Meriç Hızal, Mustafa Gürünlü, Nevzat Atalay dikkat çeken sanatçılardır.

\subsubsection{Pi Heykeli(1984)- İlhan KOMAN (1921- 1986)}

Edirneli Heykeltıraş İlhan Koman' müzede ailesi tarafından bağışlanan 9 adet eseri vardır. Bunlar 1 büst. 2 tors, 5 rölyefi ve 1 adette 4 pi heykeli $(1983-12 \times 12 \mathrm{~cm})$ dir.

Edirneli ünlü heykeltıraş İlhan KOMAN, 1921 yllında Edirne de doğmuş, İstanbul Güzel Sanatlar Akademisi, Rudolf Belling'in öğrencisi olmuştur. 1947'de, Millî Eğitim Bakanlı̆̆ı'ndan 
devlet bursu alarak Paris'e giden sanatçı, özellikle Louvre Müzesi’ndeki çalışmaları sırasında Mezopotamya ve Mısır sanatının etkilenmiştir. Burada geçirdiği süreçte çağdaş akımlara ilgi duyan İlhan Koman, ilk sergisini de 1948'de, Paris'te açmıştır.

1952'de, Anıtkabir Heykel Yarışması'nda, “Şeref Holüne çıkan merdivenlerin sağındaki kabartma kompozisyonu" birinciliğini elde etmiştir. En önemli heykelleri arasında Akdeniz Heykeli, Leonardo, Derviş, Yuvarlanan Kadın, Sonsuzluk Türevleri, Pi serisidir. Sanatçı heykellerinde biçim araştırmalarıyla beraber işlevi de amaçlamıştır.

İlhan Koman'a göre "Sanat, insanın bilinmeyene doğru çıktığı bir serüvendir” (Tunca, 2008: 82). Pi serisi heykelleri bilimle sanatın buluştuğu, matematiğin heykelle somutlaştığı eserlerdir. Sanatçı yaptığı heykeller bilimin matematiğin aracı oluyor ve nesnel olarak görünür k1lınıyor. Türkiye'nin Leonardo Vincisi olarak biliniyor.

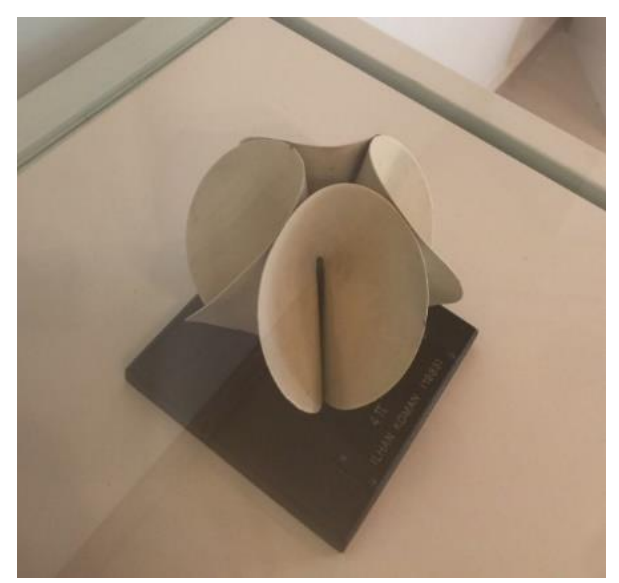

Şekil 1. İlhan Koman, Pi Serisi, 4 Pi Heykeli 12x12 cm 1983

Hüseyin Gezer “Cumhuriyet Dönemi Türk Heykeli” adlı kitabında, İlhan Koman'ın 197071 yılları arasında geometrik şekiller ve karakterler arasında deneysel çalışmalar yaptığını, topolojik yüzeylerin şekillendirilmesinde başarılı çözümler ortaya koyduğunu, biçim yapılarında belli bir geometri ve örgütlenmelerinde belirgin bir modüler düzen olmakla beraber, bu yapıtların kuruluğa düşmediklerini, birer sanat yapıtı niteliklerine ulaştıklarını yazar. (Gezer, 1984: 167)

İlhan Koman, pi sayısı içeren yüzeyler yaratarak, dairenin çapı aynı kalacak şekilde yüzeyinin pi sayısının katları ile artırılarak kıvrılmasıyla oluşan çalışmalar gerçekleştirmiştir. Birçok pi yüzey kullanılarak oluşan yüzeyler katlanıp, iç içe geçer, merkezi ve çevreyi birbirine bağlayan katmanlarca yüzeyden oluşan, şiirsel bir küre oluşur. Sanatçı mimari yapı olarak bu tasarımı düşlemiş, insanın kendini hayal gücünün sınırlarını zorlayarak çoğulluğun içinde yeniden kendini sorgulayacağını, yeniden inşa edeceğini söyler. (Tunca, 2008: 72) Belki de bu sonsuzlukta tanrısal varoluşa ulaşılabileceğine inanır.

İlhan Koman Kültür ve Sanat Vakfi'nın destekleri ile Mehmet Göğüş tarafından yapılan Pi serisinin büyük boyutlu uygulanmaları 2008 yılında Boğaziçi kampüsünde sergilenmiştir.

İlhan Koman matematik, tasarım, sorgulama gibi birçok zihinsel aktiviteyi bir arada kullanarak çağdaş heykeller yapmıştır. Pi serisi eserlerinde de ince metal saçları pi nin katları şeklinde şekil vererek bir araya getirmiştir. Müze koleksiyonunda olan eserde küçük boyutlu, ince 
metal saçtan yapılarak beyaza boyanmış bir heykeldir. Sanatçının eserleri sadece sanat tarihçilerin değil, bilim insanlarının da araştırmalarına konu olmuştur.

\subsubsection{Mavi Süreç (1993)- Meriç HIZAL (1943-...)}

İstanbul doğumlu sanatç1, MSGSÜ heykel bölümünde öğretim üyesi olarak yıllarca çalışmış ve aynı kurumdan emekli olmuş, Işık Üniversitesi öğretim üyesi olarak görev yapmaktadır. Farklı malzemeler bir arada kullanarak oluşturduğu heykellerinde, geometrik farklı biçimlerden oluştuğu, bazen yazı ve renginde biçime katkı sağladığı görülmektedir.

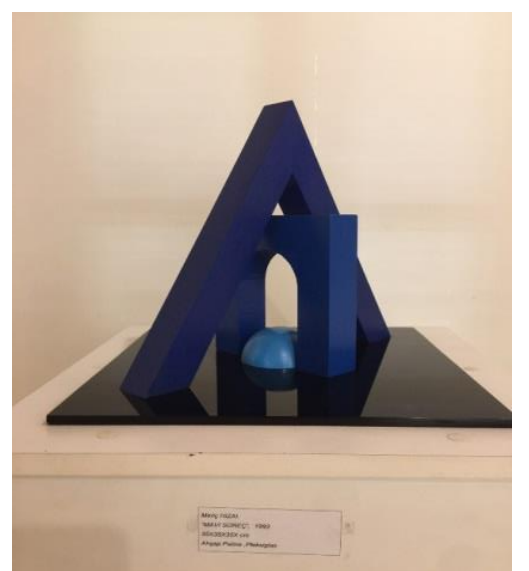

Şekil 2. Meriç Hızal, Mavi Süreç $35 \times 35 \times 35 \mathrm{~cm}, 1993$

Kaya Özsezgin Meriç Hızal eserlerini şöyle yorumlamıştır;

"Kimi yerde piramidal bir yapıyı, kimi yerde parçalanmış yerkabuğunu düşündürecek geometrik biçimleri ele alıyor. Bu biçîmleri kendi bütünlügü içinde parçalara bölerek, ara katman malzemeleri kullanıyor. Mat ve parlak yüzeyleri karşı karşıya getirerek, çatışkıları yorumlamaya çalışıyor. Sonuç olarak ilginç bir form-mekân ilişkisi ve bu ilişkiye dayanan biçimsel analizler yakalamayı başaran Hızal'ın heykelleri, son aylarda renklenmeye başlayan bu alana yeni bir katkı getirmektedir"(Özsezgin,1990).

Müze Koleksiyonunda bulunan "Mavi Süreç" adlı eseri, ahşap ve polyester malzeme beraber kullanılarak geometrik biçimlerle oluşturulan bir yapıdır. Çocukluğunda bir dönemi Edirne'de geçiren sanatçı, buradaki dini mimariden etkilenmiş olabileceği düşünülmektedir. Piramidal üçgen gökyüzüne yükselişi simgeler. Altındaki dikdörtgen tarihi bir yapının girişini göstermektedir. Heykelin oturduğu zeminde geometrik düzenin altında plastikten yapılmış küre dünyadan evrene yükselişi sembolize ediyor. Heykelin bütününde mavi rengin kullanımı, gökyüzünü yükselişi renkle güçlendirdiğini göstermektedir.

\subsection{Resim Sanatından Seçki}

Müze koleksiyonunun yarıya yakınını yağlıboya tablolar oluşturur. Türkiye de olduğu kadar dünyada da ünlü olan birçok sanatçının resimleri, müzeye değer katmaktadır. 193 sanatçının 362 yağlıboya tablo dönüşümlü olarak sergilenir.

\subsubsection{Can’t Buy Me Love (1997)- Burhan DOĞANÇAY (1929-2013)}

1929 yılında İstanbul'da doğan sanatçı, babası ressam Adil Doğançay da etkisiyle resim sanatına ilgisi ve yeteneğini geliştirmiştir. 1987'de 1. İstanbul Bienali'ne katılmış. Sanatçının resimleri Guggenheim Müzesi'nde ve daha birçok müzede bulunmaktadır. Beyoğlu'nda kendi adına müze açmış, babasının ve kendisinin eserleri bu müzede sergilenmektedir. 
Burhan Doğançay, soyut kavramsal bir sanat anlayış ile duvarlar üzerindeki aşınmış ve yıpranmış kâğıt ilanlardaki görsel etkilerden yararlanarak, tuvallerinde espas ve üçüncü boyut arayışlarına ilişkin çalışmalar yapmıştır.

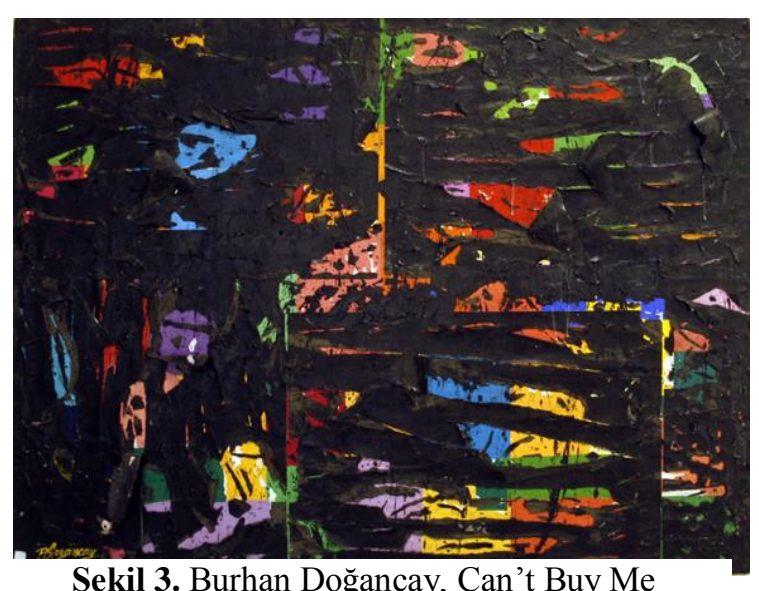

Şekil 3. Burhan Doğançay, Can’t Buy Me Love, $127 \times 102 \mathrm{~cm}, 1997$

Sezar Tansuğ Çağdaş Türk Sanatı adlı kitabında Doğançay’ın eserleri üzerine görüşlerini şöyle yorumlamışır;

"Kent halkının bir resim kâğıdı gibi kullandıkları duvar yüzeyleri üzerine geniş bir gözlem ve araştırmaya girmiş, dünyanın bazı büyük kentlerinde (New York, Berlin ve Kahire vb) duvar yüzeyinden çektiği fotoğrafları, içeriklerini yansıtmayı amaçlayan bir yorum tasnifiyle, bir katalog yayını haline getirmiştir" (Tansuğ, 1999: 267).

Sanatçının müze koleksiyonundaki "Can't buy me love" adlı eseri tuval üzeri karışık teknikle yapılmış ve İlhan Koman Heykel ve Resim Müzesinin en değerli eseridir. Can’t Buy Me Love (1997), resim yüzeyine renkli kağıtlar yapıştırılmış, siyah asfalt kaplama membran yer yer soyularak, içinden bize doğru gelen ana ve ara renklerin bütünselliğinde oluşan bir resimdir. Espas tuval yüzeyinden seyirciye doğru açılır. Soyulan membranlar tuval yüzeyinden sarktığ de yaratır. Sanatçının esin kaynağı duvarlara yapıştırılan, yırtılan, afişler karalamalar ve lekelerdir. Buralardan yola çıkarak, çağdaş resim soyutlamalarında bazen kaligrafiye varan üslubuyla, insanlar arasındaki iletişimi ve tüketim sorunsalı sorgulamıştır.

\subsubsection{Hayat için Sanat (1997)- Devrim ERBİL (1937-...)}

Devrim Erbil 1937 yılında Uşak'ta doğmuş ve yaşarken eserleri çok iyi paralara satılan nadir Türk ressamlarındandır. Devrim Erbil, geleneksel minyatür ve tasvir sanatımızdan esinlenerek çizgisel ve farklı bakış açılı perspektiflerin kullanıldığı bir yüzey duyarlığını geliştirmiştir. Resimlerinde temel işlevi üstlenen genellikle çizgidir, desendir. Renk ve leke ise ikinci planda tamamlayan bir öğedir. Başlangıçta Ağaçlar, kuşlar ve daha sonra İstanbul vazgeçemediği en önemli temalardır.

Müzedeki eseri, monokrom desen tadında soyutlanmış uçan kuşlardır. Yüzeyde devinim yapan, çizginin, yer yerde lekenin ön plana çıktığı uçan kuşların ritmini hissettiren resim, bize kuşların göçünü hatırlatır. Erbil'in "Hayat için Sanat" ismini verdiği eser, birçok anlamı içinde barındırır. Konusunu, ilhamını doğal hayatın içinden alan sanatçı, varoluşu, hayatı sanat yapmayla bütünleştiriyor. 


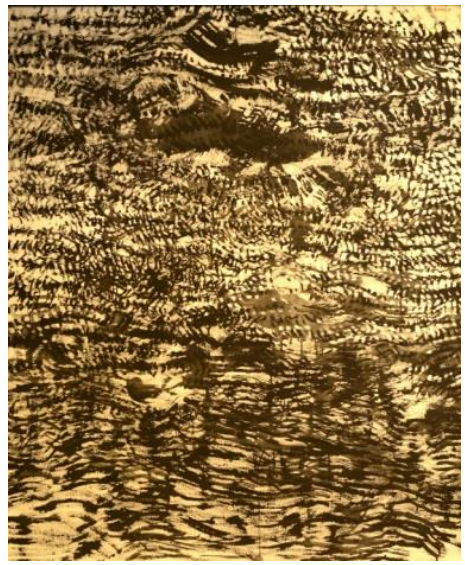

Şekil 4. Devrim Erbil, Hayat

için Sanat, 110x90 cm, 1997

Mehmet Ergüven "Yoruma Doğru" adlı kitabında, Erbil'in, kuşlarla birlikte yeni bir doğa çeşitlemesine girdiğini, sanatçının "Ritimsel soyutlama", Doğa ve Ritim Çeşitlemesi", "Titreşim" vb. verdiği adlar, neyle hesaplaşmaya giriştiğine ilişkin ipuçları verdiğini söyler. "Erbil'deki ritim tutkusunun, zaman kavramıyla iç içe bulunan müzik ile değil, doğrudan doğruya doğayla ilgili bir gerçeğin etkisinde olduğunu görüyoruz" (Ergüven, 1992: 176). Sanatç1, müzede olan eserinde Mehmet Ergüven'in üzerinde durduğu gibi doğada zamanla oluşan dönüşüm ve tekrarlara ilişkin duygulanımlarını görselleştirmiştir.

\subsubsection{Gelin (2000) - Mehmet PESEN (1923-2012)}

1923 y1lında İstanbul'da doğmuş, İDGSA (şu anki MSGSÜ), Resim Bölümü, Bedri Rahmi Eyüboğlu atölyesinde öğrenim görmüştür. Atölyedeki arkadaşları ile birlikte On'lar Grubu'nun kuruluşunda yer almıştır. Kendi anlatımı ile doğayı naif bir yorumla ele almıştır. Minyatürden yola çıkarak, kendi üslubunu bulmuştur. Anadolu'nun gelenek-görenekleri, halk oyunları, Karadeniz, Bodrum, Kapadokya yörelerini konu olarak işlemiş, öyküsel, şiirsel bir yoruma yer vermektedir. Öğrencilik yillarında sahaflarda cilt ve ebru yapan Pesen, ebruyu daha sonra resimlerinde kullanmıştır. Bazı yağlıboya tuvallerinin etrafına yaptığı ebru bordür, geleneksel öğelerin kullanıldığı çağdaş bir etki yaratmaktadır.

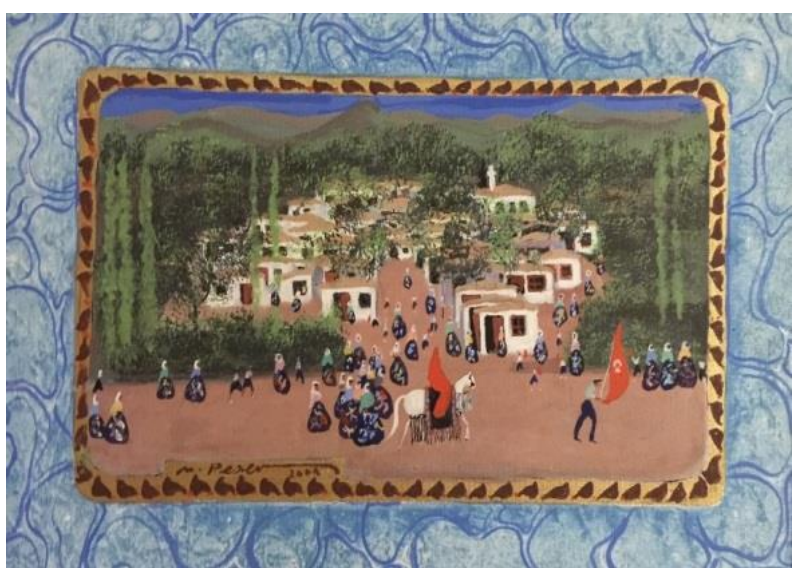

Şekil 5. Mehmet Pesen, Gelin, 30x45 cm, Tuval üzeri yağlıboya, 2000 
Müzede bulunan eseri, Anadolu köy düğününü anlatmaktadır. Gelin erkek evine beyaz at üzerinde bayrak eşliğinde götürülmektedir. Arkasında geline eşlik eden kız tarafı kadınları ve etrafta şalvarlar giymiş köylü kadınları ve çocuklar, bayrağı taşıyan dışında resimde hiç erkek olmaması manidar görülmektedir. Dağın yamacına kurulmuş, beyaz boyalı köy evleri, kompozisyonda başat rol oynamaktadır. Figürlerin küçük ve naif resmedilmesi algıyı zorlaştırmasına rağmen konuyu basit bir şekilde izleyiciye aktarılmaktadır. Sanatçının, Müzemizde bulunan Gelin resminin bordürlerinde ebru kullanması ve sınırlarının belli olması, sanki ekrandan verilen görüntü, dondurulmuş an algısını oluşturarak film sahnesi etkisi yapmaktadır.

\subsection{4. İsimsiz (1992)- Hüseyin ALTAYLI (1935- 2014)}

Hüseyin Altaylı, 1935 Bulgaristan doğumlu ve yaşamının son yıllarını Edirne de geçiren bir sanatçıdır. 121 adet eserini ailesi tarafindan müzemize bağışlanmıştır. İstanbul Devlet Güzel Sanatlar Akademisi, Zeki Faik İzer atölyesinden mezun olmuştur. Neşet Günal, Halil Dikmen ve Bedri Rahmi Eyüboğlu, öğrenimi sırasında sanatçıya özel ilgi göstermiş ve birçok konkurlarda önemli ödüller almıştır. 1966 İspanya Devlet bursu ile İspanya'da, 1969 Paris'te, çalışmalarını sürdürmüştür. Birçok özel lisede resim ve fotoğraf öğretmenliği yapan sanatçı, hayatının son döneminde Trakya Üniversitesi, Devlet Konservatuvarında lisans düzeyinde estetik dersleri vermiştir. D grubu sanatçılarının üzerindeki etkisi resimlerinden anlaşılmaktadır. Eserlerinde doğa ve özellikle İstanbul teması dikkat çeker. Zengin renk tonları, biçimin iyi analizi, ışığın kendine özgü yorumlanması eserlerinin temelini oluşturur.

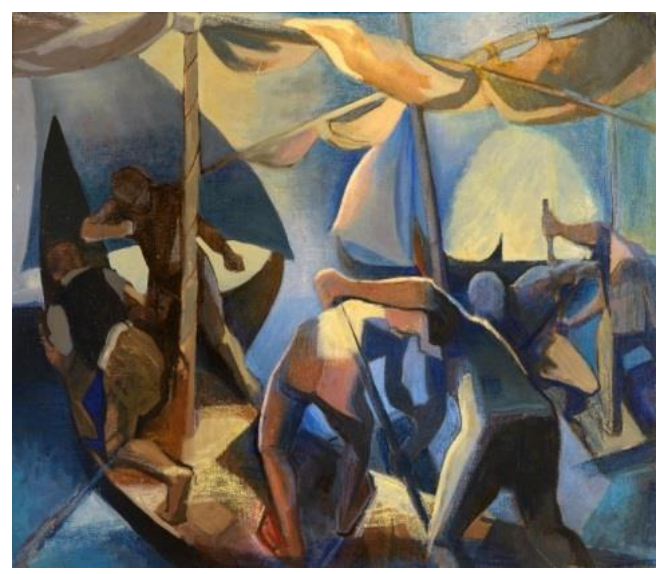

Şekil 6. Hüseyin Altaylı, İsimsiz, TÜY $95 \times 120 \mathrm{~cm}, 1992$

r. Yelkenleri toplanmış iki

Araştırmaya dâhil edi sandal ve kürekleri ellerinde gemiciler. Sanatçı, Mavi-Turuncu karşıt renk uyumunu kullanmış, biçimleri analitik planlarına göre iki rengin gri tonlarıyla vermiştir. Yağlıboya ile yaptığı resmin üzerine pastelle belli yerlerine müdahale ederek dokusal zenginlik katmıştır. Resmin bütününe hâkim mavi renk iki ton olarak pastelle resme sonradan eklenmiştir. Hareketli bir kompozisyona sahip olan resmin odak noktası, öndeki iki figürdür. İki rengin zengin tonları ile hem hareketi vermiş hem de kompozisyon kurgusunu altın oranı gözeterek yaptığı, güçlü resimlerinden biridir.

\subsubsection{Gitme (2002)-Onay AKBAŞ (1964-..)}

Onay Akbaş 1964'de Fatsa'da doğmuş, 1988'den bu yana Paris'te atölyesinde çalışmaktadır. Resimlerinde çoğul anlamıyla İktidarları (av-avcı, oyun- oyuncak) sorguluyor. İnsan ve insanla ilgili her şey (oyun, hiyerarşi, iktidar) Onay Akbaş'ın konuları arasında yer alabiliyor. Eserlerinde primitif, kendine özgü imgelerle, renk ve dokuyu kullanarak yüzey üzerinde oyun oynamaktadır. 


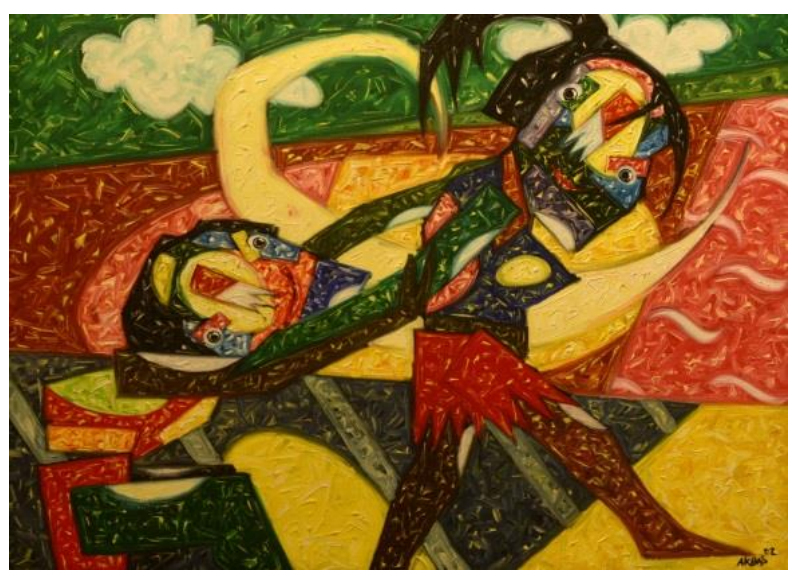

Şekil 7. Onay Akbaş, Gitme, 60x70, 2002

İlhan Koman Heykel ve Resim Müzesindeki eserinde, iki figür arasında geçen bir mücadeleyi görmekteyiz. Aslında öndeki figür gücü almış ve arkadakini kendine doğru sürüklüyor gitmesini istemiyor. Resmin kompozisyonu çok iyi kurgulanmış. Odak noktası öndeki figür olarak planlanmış. Figürler Kızılderilileri anımsatıyor. Burunları, gözleri, çene yapıları oldukça vahşi gözükmektedir. Farklı yorumlamaya açık ve hareketin çok iyi verildiği bir eserdir. Kırmızı, sarı ve yeşil renk neredeyse eşit miktarda yüzeyi kapliyor.

\subsection{Baskıresim Koleksiyonundan Seçki}

Mustafa Aslıer başta olmak üzere Türk ve Balkanlardan özgün baskıresim sanatçılarından birçok sanatçının eseri müze koleksiyonunda karşımıza çıkar. Müze, Hasan Pekmezci, Atilla Atar, Süleyman Saim Tekcan, Hatice Bengisu, Güngör Taner, Jochan Jotow, Devrim Erbil başta olmak üzere 41 sanatçının 65 adet farklı tekniklerde baskıresim koleksiyonuna sahiptir.

\subsection{1. İkizler (2012)- Mustafa ASLIER (1926-2015)}

Mustafa Aslıer 1926 Bulgaristan'da doğumlu sanatçı, Ankara Gazi Eğitim Enstitüsünden sonra, Münih Grafik Sanatlar Akademisi ve Stuttgart Grafik Sanatlar Yüksek Okulu'nda öğrenimini tamamlamıştır. Yurda döndükten sonra şu anki Marmara üniversitesi Güzel Sanatlar Fakültesi Grafik bölümünde çalışmaya başlamış ve baskıresim atölyesini kurmuştur. Türkiyede baskıresmi teriminin özgün baskıresmi olarak kullanılmasına öncülük etmiştir. Türk Özgün baskır.esmin önemli temsilcilerindendir

Mustafa Aslıer yöresel nitelikli figürleri geometrik soyutlayıcı tavırla, siyah-beyaz ve bazen renkli anlayışla metal gravür tekniğini kullanmıştır. Anadolu kökenli yalınlaştırılmış figürleri, geometrik bir yığma düzeni içinde başlangıçta gerçekçi bir şekilde aldığı insan figürünü, daha sonra yalın biçimlere dönüştürmüştür. Siyah beyaz lekelerle vermeye çalıştığı yalın figürlerle insanın duruş ve hareketini yakalamıştır. Sanatçı zamanla geleneksel Türk folklorundan etkilenerek, yöresel konularda, insanın duruş, oturuş ve hareketini, stilize ve simgesel bir ifadeyle iyice yalınlaştırarak vermiştir. 


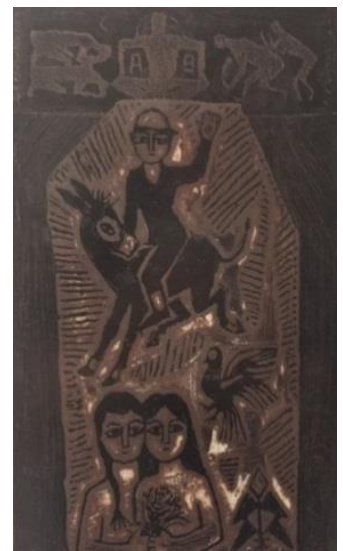

Şekil 8. Mustafa Aslıer, İkizler $32 \times 25 \mathrm{~cm}$, Metal Gravür, 2012

Müzede bulunan ikizler adlı gravüründe de yöresel öğelerin kullanıldığı, ağaç gravür etkisinde metal gravürdür. Gravürün siyah beyaz ifade gücünü çok iyi kullanmayı bilen sanatçı, figürleri de olabildiğince yalınlaştırarak konuyu açık olarak ortaya koyar. Bu gravürü keloğlan masallarından bir anı gösterir gibidir. Eşeği üzerindeki Keloğlan, sırtlarını dönmüş ikiz kız kardeşlere el sallamaktadır. Oysa onu ne gören vardır. Ne duyan...

\subsubsection{Tabletler II (2000)- Süleyman Saim Tekcan (1940-...)}

Türkiyede Baskıresim denilince ilk akla gelen kişi olan Süleyman Saim Tekcan, Anadolu Uygarlıklarından, Osmanlıdan, doğal yaşam çevresinden, sanat tarihinden etkilenmiş, kendine özgün at soyutlamaları yaptığı baskıresimleriyle tanınmaktadır. Resim sanatının temel plastik elemanları olan renk, leke, 1şık, saydamlık, kompozisyon üzerinden yağliboya tadında baskılar üretmektedir. Sanatçı, 2004 yılında açtığı İMOGA (İstanbul Grafik Sanatlar Müzesi) ve 2008 yılında düzenlenmesine öncülük ettiği I. Uluslararası Baskıresim Bienali ile baskıresim sanatının tanınmasını, sevilmesini ve yaygınlaşmasını sağlamıştır.

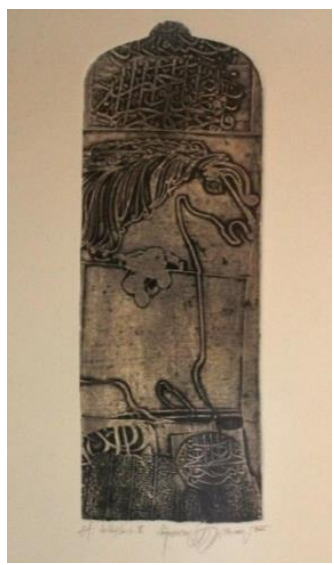

Şekil 9. S.S.Tekcan.

"Tabletler" 50x $25 \mathrm{~cm}$ 2000

Türk plastik sanatlarında At imgesi denilince ilk akla gelen sanatçıdır. Onun atları, biçimleri, soyutlaması, hareketleri ile tamamen ona aittir. Müze'de bulunan Tabletler adlı üç adet gravürü vardır. Tablet II, mezar taşı formunda merkezde atın yarı gövdesinin, üstte ve altta Osmanlı 
yazılarının olduğu bir metal gravürdür. Attaki yazılar dört farklı plan şeklinde tasarlanmış ve solda eski bir madeni para yazılarıyla dikkat çekmektedir. Bir dönem (1990) gravürlerinin ortak özelliği, at imgesi, doku, 1şıklı çizgisel ifade, Osmanlı tabletlerinden, mezar taşlarından etkilerden ortaya çıkan yazı, müzedeki gravürlerinde de karşımıza çıkmaktadır.

\subsection{Fotoğraf Sanatından Seçki}

Müze koleksiyonunda 5 sanatçının 5 fotoğraf eseri vardır. en önemli ve dikkat çeken ise Burhan Doğançayın özel basım büyük boyutlu fotoğrafıdır.

\subsubsection{Montparnesse-Paris (1981)- Burhan DOĞANÇAY (1929-2013)}

Özel ve sertifikalı basım fotoğraf olan Montparnesse-Paris adlı bu eser, Doğançay Müzesinde sergi sergilenmiş̧tir. Bir Elinde bavul ve diğer elinde katlanmış yatağı ile kameraya bize bakan bir erkek. Giyiminde anlaşıldığ kadarıyla 5 kat giyinmiş yaşamın yükünü çektiği yüzünden belli olan bıyıklı bir erkek. Duvar üzerine yapıştırılmış duvar kağıtlarında bir fotoğraf etkisi dikkat çekiyor. Siyah beyaz ve gri tonlarının etkisi çok iyi kullanılmıştır. Yırtılan kağıtlardan duvarın tuğlaları yer yer gözüküyor.

Burhan Doğançay, en karakteristik eserlerinin esin kaynaklarından olan duvar kağıtları, afişlerin bir göstergesidir bu fotoğraf. Aynı zamanda güncel problem olan göçü, göçmenliği, sığınmacılığ 1 , mülteciliği göz önüne getirerek bize gösterir.

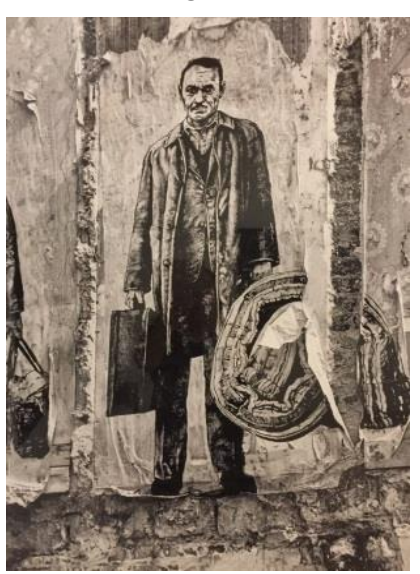

Şekil 10. Burhan Doğançay, Montparnesse, Paris Fransa, 1981, 90x60cm, Fotoğraf Bask1

\section{Sonuç}

Trakya Üniversitesi İlhan Koman Heykel ve Resim Müzesi, Anıt-Kent Edirne'nin, Balkanlar'ın ve diğer bölgelerden gelen ziyaretçilerin vazgeçilmez uğrak noktalarındandır. Müze koleksiyonunu Türk plastik sanatlarında önemli yeri olan sanatçıların eserlerinden oluşmaktadır. Her gün yüzlerce ziyaretçi alan Karaağaç Tarihi Tren istasyonunda bulunan bir müze olmasında dolay1 ziyaretçi sayısı her geçen artarak, sanatın halka ulaşmasında çok önemli bir köprü görevi üstlenmektedir. Ayrıca güzel sanatlar eğitimi veren bir fakülte ile yan yana olması, gençlere farklı eserleri bir arada görme imkânı vermekte ve eğitime direk olarak katkı sağlamaktadır.

Burhan Doğançay, Adil Doğançay, Burhan Yıldırım, Basri Erdem, Bahattin Odabaşı, Devrim Erbil, Mehmet Pesen, Onay Akbaş, Numan Pura, Mustafa Plevneli, Güngör D.Arıbal, Güngör Taner, Fehim Huskovic, Nikolay Alexiev, Tayyip Y1lmaz, Orhan Benli, Halim Çeliker, Habib Gerez, Tülin Onat, Mustafa Aslıer, İsmail Avcı, Hayri Esmer, Hasan Pekmezci, Atilla Atar, 
Jochan Jotow, Hatice Bengisu, Süleyman Saim Tekcan gibi Türkiye'nin ve Balkanların önde gelen sanatçılarının eserlerine ev sahipliği yapmaktadır.

Bir dönemin çok önemli sanatçılarını bir araya getirerek, her birinin aynı mekan ve zamanda görülmesini sağlayan Müze, Farklı tür ve teknikte çalışan sanatçıların eserlerini birlikte değerlendirmemizi, yorumlamamızı ve anlamamızı sağlamaktadır.

Sonuçta, Trakya Üniversitesi ve Türk plastik sanatları açısından çok önemli olan İlhan KOMAN Heykel ve Resim Müzesi, her geçen gün koleksiyonunu arttırarak gelecek nesillere 1şık olma yönünde ilerlemektir.

\section{KAYNAKÇA}

Eczacıbaşı, Ş. (1997). Eczacıbaşı Sanat Ansiklopedisi (Cilt 1). İstanbul: YEM Yayınları.

Ergüven, M. (1992). Yoruma Doğru. İstanbul: Yapı Kredi Yayınları.

Esmer, H. (2011). Türkiye'de Basktresme Bakmak. Eskişehir: Anadolu Üniversitesi Yayınları.

Gezer, H. (1984). Cumhuriyet Dönemi Türk Heykeli. Ankara: İş Bankası Kültür.

Tansuğ S. (1999). Çağdaş Türk Sanatı. İstanbul: Remzi Kitapevi.

Tunca, A. (2008). “Tiraşsız heykeltıraş” Edirneli İlhan Koman. Edirne: İnkılap Kitapevi.

\section{İnternet Kaynakları}

Özsezgin, K. (15 Haziran 1990). Meriç Hızal. İstanbul: Milliyet Sanat Dergisi. http://www.merichizal.com/pPages/pArtist.aspx?paID=621\&section=550\&lang=TR\&bhcp $=1 \&$ periodID $=\&$ page $\mathrm{No}=1 \&$ exhID $=0$ (Erişim: 23.09 .2019$)$

http://www.basrierdem.com/tr/(Erişim: 21.09.2019)

https://www.istanbulsanatevi.com/turk-ressamlar/devrim-erbil-hayati-ve-eserleri-1937/(Erişim: 21.09.2019)

http://www.beyazart.com/sanatci/Mehmet-Pesen (Erişim: 21.09.2019)

http://minesanat.com/meric-hizal-otobiyografimden/ (Erişim: 21.09.2019)

http://www.leblebitozu.com/turk-da-vincisi-ilhan-komanin-eserleri-ve-hayati/ (Erişim: 21.09.2019)

https://www.istanbulsanatevi.com/turk-ressamlar/onay-akbas-hayati-ve-eserleri/ (Erişim: 29.09.2019)

https://www.istanbulsanatevi.com/turk-ressamlar/mustafa-aslier-hayati-ve-eserleri/(Erişim: 04.10.2019)

http://www.suleymansaimtekcan.com/pPages/pArtist.aspx?paID=355\&section=550\&lang=ENG\&p eriodID $=\&$ pageNo $=2 \&$ exhID $=0 \& b h c p=1$ (Erişim: 04.10.2019) 